\title{
EDITORIAL
}

\section{Assessing inflammatory phenotypes and improving the cost-effectiveness of asthma and COPD care in the community}

See linked article by Tilemann et al. on pg 407

\section{*Mike Thomas ${ }^{a}$, D Robin Taylor}

a Asthma UK Senior Research Fellow, Academic Primary Care, University of Aberdeen, UK

b Professor of Respiratory Medicine, Dunedin School of Medicine, University of Otago, New Zealand

${ }^{*}$ Correspondence:

Dr Mike Thomas,

Asthma UK Senior Research Fellow

Academic Primary Care

University of Aberdeen

Polwarth Building

Foresterhill

AB25 2ZD

Tel: +44 (0)7753 719867

E-mail: mikethomas@doctors.org.uk

Commissioned article

Not externally peer-reviewed

Accepted 26th August 2011

Online 19th October 2011
Asthma and chronic obstructive pulmonary disease (COPD) are common diseases, but diagnosis can be difficult within the constraints of primary care. The presenting symptoms of both conditions are non-specific and overlapping. Although questionnaires on symptoms and exposures can help in screening for and differentiating between asthma and COPD, objective confirmation is required before a diagnostic label is applied (generally for life) and long-term treatment commenced.

COPD diagnosis is relatively straightforward where there is access to spirometry; demonstration of fixed airways obstruction, usually in a smoker or ex-smoker, defines the disease. Diagnosing asthma is more difficult; lung function is often normal in the absence of triggers, and 'pseudo-asthma' (for example dysfunctional breathing) may spuriously suggest variable airflow obstruction. Under-diagnosis and misdiagnosis of COPD, ${ }^{1}$ and over-diagnosis of asthma, ${ }^{2}$ are commonly reported. Up to a quarter of patients labelled as having asthma lack objective confirmation of the disease. The reason for distinguishing between asthma and COPD is that they are different diseases with different pathophysiological characteristics and different guideline-defined treatment algorithms. In particular, low-dose inhaled corticosteroids (ICS) have an early and pivotal role in most cases of asthma but should be used more selectively and at higher doses in COPD. Long-acting bronchodilators are used as monotherapy in COPD, but only as an additional treatment to ICS in asthma. But making such a distinction is itself difficult. So how can we do better and why should we?

The use of alternative objective tests, such as biomarkers, is one possibility. A biomarker is a surrogate measurement designed to characterise and quantify an underlying disease process ${ }^{3}$ and may correlate only weakly with symptoms. Airways and systemic inflammation play an important role in the pathogenesis and clinical manifestations of asthma and COPD. Heterogeneity in the type and intensity of inflammation occurs between and within individuals over time in both diseases, with implications for therapy and for prognosis. ${ }^{4.5}$ Biomarker-based assessment of inflammation may therefore have a role in diagnosis and targeting treatment.

A number of potentially useful respiratory biomarkers have been described, although how we can integrate these into routine care is less clear. ${ }^{3}$ The simplicity of measurement and relatively low cost of some biomarkers indicate their potential for routine use. In primary care it is feasible to obtain prognostic markers based on blood tests - e.g. C-reactive protein (CRP), serum immunoglobulin $\mathrm{E}(\mathrm{IgE})$ levels, and blood eosinophil counts. Measurement of the fraction of exhaled nitric oxide ( $\left.\mathrm{F}_{E} \mathrm{NO}\right)$, a simple and inexpensive technology for assessing eosinophilic airway inflammation, ${ }^{6}$ is also viable in routine general practice. ${ }^{7} \mathrm{~F}_{\mathrm{E}} \mathrm{NO}$ measurement has a role where there is diagnostic difficulty, ${ }^{8}$ in recognising different patterns of disease (i.e. phenotypes), ${ }^{9}$ and in identifying those at risk of adverse outcomes (e.g. exacerbations). ${ }^{10} \mathrm{FENO}$ is most useful in targeting those patients who will benefit from antiinflammatory treatment. ${ }^{8}$ In difficult, poorly controlled asthma, where symptoms may be due to more than one cause, $\mathrm{F}_{\mathrm{E}} \mathrm{NO}$ measurement can be used predictively to avoid unnecessary and futile increases in steroid therapy."1

In this issue of the $P C R J$, Tilemann et al. report the utility of biomarkers in the diagnosis and differentiation of asthma and COPD. ${ }^{12}$ Over 200 symptomatic undiagnosed patients underwent a standardised evaluation centred firstly on physiological assessments. Based on the outcomes, patients were then placed into four groups: 'asthma', 'COPD', 'partial 
reversibility' and 'no obstructive lung disease'. In addition, four biomarkers were measured: CRP, IgE, blood eosinophil count and $\mathrm{F}_{\mathrm{E} N O}$. The relationship between each biomarker and the subsequent diagnosis was investigated. Differences were observed between groups. COPD cases had significantly higher levels of CRP than asthma patients, although with considerable scatter and overlap. Asthma cases had higher $\mathrm{F}_{\mathrm{E} N \mathrm{~N}}$, blood eosinophil and $\lg \mathrm{E}$, although again there was wide scatter and overlap. These results are intuitively correct; one would expect that those patients with COPD would have greater systemic inflammatory activation and those with asthma more atopy and eosinophilic inflammation.

When assessing diagnostic tests it is important to know the performance characteristics based on sensitivity (the ability to identify positive results, so helping 'rule out' a diagnosis if negative) and specificity (the ability to identify negative results, helping 'rule in' if positive). In Tilemann et al's paper, ${ }^{12}$ receiver-operating characteristic (ROC) curves for each biomarker were constructed, and optimal cutoff values estimated. Consistent with other research, the sensitivities and specificities of $\mathrm{FENO}_{\mathrm{ENO}}$ showed that it is a good test for ruling asthma out but not so good at ruling it in. Similar but less discriminatory findings were reported for blood eosinophilia (possibly an under-rated investigation) and raised lgE. CRP had reasonable sensitivity but a specificity of only 50\% for COPD, so had a high false positive rate.

Where does this leave us? In patients with non-specific respiratory symptoms, a raised CRP makes COPD more likely, especially if spirometry is abnormal. Markers of eosinophilic inflammation or allergy make asthma more probable. Clearly, exploring the relationship between these biomarkers and treatment responsiveness would be the next logical step in these authors' investigations. A limitation of this paper ${ }^{12}$ is that it focusses on the differentiation between asthma and COPD but doesn't 'drill deeper'. This is understandable but unfortunate. Our current guideline-based approach encourages us to treat patients as if they were all the same once they are diagnosed. However, given that asthma and COPD are such heterogeneous conditions, with recognisable but overlapping phenotypes, a multidimensional assessment of patients with airways diseases is required. ${ }^{13}$ We should perhaps pay less attention to the diagnostic label and more to risk stratification and targeted treatment. For example, eosinophilic inflammation is a marker of steroid responsiveness regardless of diagnosis. ${ }^{14}$ Arguably, it is more important to characterise the underlying pathology - i.e. airway inflammation - rather than physiology, in guiding therapy. Even in primary care, phenotypespecific treatment may lead to better outcomes and more appropriate targeting of therapy.

In these days of financial constraints, there is an additional reason for this approach. Approximately $30 \%$ of patients with asthma do not achieve good control despite maximum doses of ICS. ${ }^{15}$ Approximately $85 \%$ of patients with COPD do not respond symptomatically to inhaled steroid (although in a subset, exacerbations may be reduced). Yet in asthma, guidelines recommend a step-wise increase in antiinflammatory treatment for all patients, and in COPD the majority of patients receive ICS, often sooner rather than later. The cost implication of ineffective treatments is large. There is potential for reducing this cost substantially, and simultaneously improving the quality of patient care by more accurate phenotypic assessment and targeted treatment. This should be applicable in primary care and should not just be the prerogative of secondary and tertiary care.

\section{Conflicts of interest}

MT is an Associate Editor of the PCRJ, but was not involved in the editorial review of, nor the decision to publish, this article. DRT declares that he has no conflicts of interest in relation to this article.

\section{References}

1. Walters JA, Walters EH, Nelson M, et al. Factors associated with misdiagnosis of COPD in primary care. Prim Care Respir J 2011;20:396-402. http://dx.doi.org/10.4104/pcrj.2011.00039

2. Luks VP, Vandemheen KL, Aaron SD. Confirmation of asthma in an era of overdiagnosis. Eur Respir J 2010; 36: 255-60. http://dx.doi.org/ 10.1183/09031936.00165109

3. Taylor DR. Using biomarkers in the assessment of airways disease. J Allergy Clin Immunol 2011:in press. http://dx.doi.org/10.1016/j.jaci.2011.03.051

4. Berry M, Morgan A, Shaw DE, et al. Pathological features and inhaled corticosteroid response of eosinophilic and non-eosinophilic asthma. Thorax 2007;62:1043-9. http://dx.doi.org/10.1136/thx.2006.073429

5. Brightling CE, Monteiro W, Ward R, et al. Sputum eosinophilia and short-term response to prednisolone in chronic obstructive pulmonary disease: a randomised controlled trial. Lancet 2000;356:1480-5. http://dx.doi.org/10.1016/S0140-6736(00)02872-5

6. Berry MA, Shaw DE, Green RH, Brightling CE, Wardlaw AJ, Pavord ID. The use of exhaled nitric oxide concentration to identify eosinophilic airway inflammation: an observational study in adults with asthma. Clin Exp Allergy 2005;35:1175-9. http://dx.doi.org/10.1111/j.1365-2222.2005.02314.x

7. Gruffydd-Jones K, Ward S, Stonham C, McFarlane T, Thomas M. The use of exhaled nitric oxide monitoring in primary care asthma clinics: a pilot study. Prim Care Respir J 2007;16:349-56. http://dx.doi.org/10.3132/ pcrj.2007.00076

8. Smith AD, Cowan JO, Filsell S, et al. Diagnosing asthma: comparisons between exhaled nitric oxide measurements and conventional tests. Am J Respir Crit Care Med 2004;169(4):473-8. http://dx.doi.org/10.1164/rccm.200310$13760 \mathrm{C}$

9. Dweik RA, Sorkness RL, Wenzel S, et al. National Heart, Lung, and Blood Institute Severe Asthma Research Program. Use of Exhaled Nitric Oxide Measurement to Identify a Reactive, At-risk Phenotype Among Patients With Asthma. Am J Respir Crit Care Med 2010;181(10):1033-4. http://dx.doi.org/10.1164/rccm.200905-06950C

10. Gelb AF, Flynn Taylor C, Shinar CM, Gutierrez C, Zamel N. Role of spirometry and exhaled nitric oxide to predict exacerbations in treated asthmatics. Chest 2006;129(6):1492-9. http://dx.doi.org/10.1378/chest.129.6.1492

11. Pérez-de-Llano LA, Carballada F, Castro Añón O, et al. Exhaled nitric oxide predicts control in patients with difficult-to-treat asthma. Eur Respir J 2010;35(6):1221-7. http://dx.doi.org/10.1183/09031936.00118809

12. Tilemann L, Gindner L, Meyer F, Szecsenyi J, Schneider A. Differences in local and systemic inflammatory markers in patients with obstructive airways disease. Prim Care Respir J 2011;20:407-14. http://dx.doi.org/10.4104/ pcrj.2011.00069

13. Anderson G. Endotyping asthma: new insights into key pathogenic mechanisms in a complex, heterogeneous disease. Lancet 2008;372:1107-19. http://dx.doi.org/10.1016/S0140-6736(08)61452-X

14. Smith AD, Cowan JO, Brassett KP, et al. Exhaled nitric oxide: a predictor of steroid response. Am J Respir Crit Care Med 2005;172:453-9. http://dx.doi.org/10.1164/rccm.200411-14980C

15. Bateman ED, Boushey HA, Bousquet J, et al. GOAL Investigators Group. Can guideline-defined asthma control be achieved? The Gaining Optimal Asthma Control study. Am J Respir Crit Care Med 2004;170(8):836-44. http://dx.doi.org/10.1164/rccm.200401-0330C 